\title{
An Investigation of Knowledge, Attitudes, and Practices Concerning Asthma among Patients in Tabuk, Saudi Arabia
}

\author{
Abeer Alatawi* ${ }^{1}$, Ali Alghamdi ${ }^{2}$ \\ ${ }^{1}$ Department of Nursing, Faculty of Applied Medical Sciences, Tabuk University, Saudi Arabia \\ ${ }^{2}$ Department of Radiological Sciences, Faculty of Applied Medical Sciences, Tabuk University, \\ SaudiArabia
}

*Corresponding Author: Dr. Abeer Alatawi, Department of Nursing, Faculty of Applied Medical Sciences, Tabuk University, Saudi Arabia.

\begin{abstract}
Background: Sufficient knowledge and positive attitudes among patients with asthma are prerequisites for managing the potential risks of asthma symptoms and providing optimal treatment.

Aims and Objectives: The aim of this study is to evaluate the knowledge and attitudes of asthmatic patients regarding asthma and to determine the gap between their knowledge and proper practices to alleviate dangerous symptoms.

Methods: A cross-sectional study was conducted from February to April 2019 at two governmental hospitals in Tabuk city. Only those asthmatic patients who met the inclusion criteria (aged $\leq 18$ years old) were recruited. Both genders were considered in this study. This study excluded those who had other chronic diseases than asthma.The participants were selected from specific clinical area settings (outpatient clinic, Emergency Room, medical and surgical wards), using purposive sampling method. Returned responses numbered 112, with a response rate of 56\%.Asthma Knowledge Questionnaire (AKQ) was used, based on previous studies, to evaluate their knowledge and attitudes concerning asthma symptoms. All data were analyzed descriptively using the Statistical Package for Social Sciences (SPSS).Descriptive statistics of percentage, mean, frequency and standard deviation were applied.

Results: Of the 112 total respondents (52.7\% female and $47.3 \%$ male), $40 \%$ declared that they had heard of this disease from a healthcare professional (doctor or nurse), 24\% from the internet, and only $4 \%$ from television. Overall, 100\% of participants reported thatasthma can becaused by an allergy, air pollution, or any other type of irritant (dust, fumes, etc.); $83.9 \%$ believed that the common cold and exercise can lead to asthma; 79.5\% thought that asthma is life-threatening; and 59.8\% said that asthma is a genetic disease. Approximately $18 \%$ believed that asthma is not a dangerous disease; $82 \%$ reported that inhalers are the best medical intervention to alleviate asthma symptoms; and only $11 \%$ said that medication should be continued even if symptoms no longer occur.

Conclusion: Educational programs about asthma should be adopted in health systems to improve the knowledge, attitudes, and practices of patients and their families regarding asthma attacks, in order to prevent acute exacerbations.
\end{abstract}

Keywords: Asthma, knowledge, attitudes, patients, education programs

\section{INTRODUCTION}

Asthma is defined as a long-term condition characterised by a history of respiratory symptoms, such as episodes of wheezing, shortness of breath, chest tightness, and a cough. These symptoms vary in intensity over time (1). Asthma is a potentially life-threatening condition and one of the most common respiratory problems, causing lung airway obstruction. Asthma places a significant social and economic burden on patients, families, and healthcare systems (1). Although this disease has no cure, it can be controlled by the use of appropriate medication and effective selfmanagement through education (2).

An estimated 300 million people globally are currently asthmatic (3). In Saudi Arabia, asthma is the most common chronic disease resulting in hospital admissions among adults, primarilydue to heavy pollution from cars and factories (both of which are increasing in number) (4). It is estimated that approximately two million people in the country suffer from asthma (5). In addition, a recent asthma control survey showed that the conditions of only $5 \%$ of patients were controlled, $31 \%$ were partially controlled, and 
An Investigation of Knowledge, Attitudes, and Practices Concerning Asthma among Patients in Tabuk, Saudi Arabia

64\% were uncontrolled (6). Most relevantstudies have been conducted on the risk factors and prevalence of asthma among the patients $(7,8,9$, 10,11,12,13), but few studies have been performedon educating the population of Saudi Arabia $(14,15)$.

\section{BACKGROUND}

Patients living with asthma require a significant amount of support, guidance, and education to manage their condition effectively (16). This education should be delivered by health professionals having a suitable level of knowledge in this field. Currently, there is inconsistency in the standards of asthma management provided to asthmatic patients (17). Asthma management is challenging for healthcare professionals because the causes and triggers of asthma are not fully understood, although numerous studies have investigated factors including internal and external environmental elements and family history (18). Other factors that aggravate this situation include under-diagnosis, lack of education, poor healthcare facilities, and limited treatment options (19). Despite several decades of advances in the control and management of asthma, it remains a common worldwide health and socioeconomic problem (9). Poor control of asthma may lead to hospitalization, school absence, frequent use of emergency departments, and even death in severe cases. Over recent decades, asthma and its management have come to be seen as a major global public health concern (20).

Although research on asthma has increased and taken a prominent place in asthma management worldwide, empirical studies focusing on the asthma knowledge of patients are lacking. Furthermore, no study has been done to assess asthma knowledge and attitudes among patients in Tabuk city, in Saudi Arabia.

\section{OBJECTIVES}

1. To assess asthma knowledge, attitudes, and practices among patients with asthma in Tabuk, Kingdom of Saudi Arabia.

2. To identify asthma-control challenges in the study population.

\section{Materials ANd Methods}

We conducted a cross-sectional descriptive study from February to April 2019 within two governmental hospitals King Khaled Hospital $(\mathrm{KKH})$ and King Fahd Specialised Hospital
(KFSH) in Tabuk, Kingdom of Saudi Arabia. The 112 subjects were recruited from these two hospitals. Purposive sampling used in this study. All participants fulfilled the inclusion criteria, consented to participation in the study, were at least 18 years old and above, and were diagnosed with asthma or had a history of asthma. We clearly explained the study objectives to the participants and obtained written consent from all of them. Their right to refuse participation and their right to confidentiality were communicated. We obtained ethical approval from the IRB committee at the University of Tabuk. There were no potential risks from the research.

\section{Sample Size and Setting}

We distributed approximately 200 questionnaires at the two hospital sites. Participants were recruited from specific clinical area settings (outpatient clinic, Emergency Room, medical and surgical wards).Returned responses numbered 112 , with a response rate of $56 \%$.

We developed the questionnaire based on our study objectives and after conducting a literature review of similar studies. Questions were adapted from questionnaires used in several previous studies to evaluate the knowledge of patients with asthma (21-22). We prepared the questionnaire in a bilingual (English and Arabic) format, which was reviewed by an Allergy and Immunology consultants who assessed all of the requirements for the questionnaire. The questionnaire contained questions on demographic data, knowledge of the aetiology and pathophysiology of asthma, asthma medications, and beliefs and attitudes on asthma. Although several instruments have been developed to survey knowledge and perceptions about asthma among asthma patients, it appears that no published survey instrument has been specifically designed to provide insights into the knowledge and perceptions of asthma patients in a hospital setting.

\section{RESULTS}

We included in our study a total of 112 adults (52.7\% female and $47.3 \%$ male) with a mean age of 44 years from two public hospitals (King Khaled Hospital and King Fahd Specialist Hospital). Those who did not complete the survey were excluded from the study. The demographic characteristics of the participants are shown in Table 1. 
An Investigation of Knowledge, Attitudes, and Practices Concerning Asthma among Patients in Tabuk, Saudi Arabia

Table1. Demographic characteristics of the study population

\begin{tabular}{|c|c|c|c|}
\hline & & Number & Percent \% \\
\hline \multirow[t]{2}{*}{ Gender } & Male & 59 & 52.7 \\
\hline & Female & 53 & 47.3 \\
\hline \multirow[t]{5}{*}{ Age } & $18-30$ & 47 & 42.0 \\
\hline & $31-40$ & 33 & 29.5 \\
\hline & $41-50$ & 24 & 21.4 \\
\hline & $>50$ & 8 & 7.1 \\
\hline & & & 0.0 \\
\hline \multirow[t]{8}{*}{ Education } & Primary school & 10 & 8.9 \\
\hline & Elementary school & 12 & 10.7 \\
\hline & High School & 45 & 40.2 \\
\hline & Diploma & 13 & 11.6 \\
\hline & Bachelor & 17 & 15.2 \\
\hline & Postgraduate studies & 2 & 1.8 \\
\hline & No education & 13 & 11.6 \\
\hline & & & 0.0 \\
\hline \multirow[t]{3}{*}{ Employment } & Employed & 49 & 43.8 \\
\hline & Not employed & 63 & 56.3 \\
\hline & & & 0.0 \\
\hline \multirow[t]{2}{*}{ Smoking } & Smoker & 27 & 24.1 \\
\hline & Non-smoker & 85 & 75.9 \\
\hline
\end{tabular}

The largest category encompassed those aged 18 to $30(n=47,42 \%)$; the number of participants per category decreased with age until it reached $8(7 \%)$ for those over age 50. Considering participants' educational achievement, 45(40.2\%) participants had completed high school and only 2(1.8\%) had completed postgraduate studies. Forty-nine participants $(43.8 \%)$ were employed while 63(56.3\%) were unemployed. In addition, 27(24.1\%) were smokers and $85(75.9 \%)$ were non-smokers. In this survey, $40 \%$ declared that they had heard of this disease from a healthcare professional (doctor or nurse), $24 \%$ from the internet, $16 \%$ from friends, $10 \%$ from journals and newspapers, $9 \%$ from books or leaflets, and only $4 \%$ from television (Figure 1).

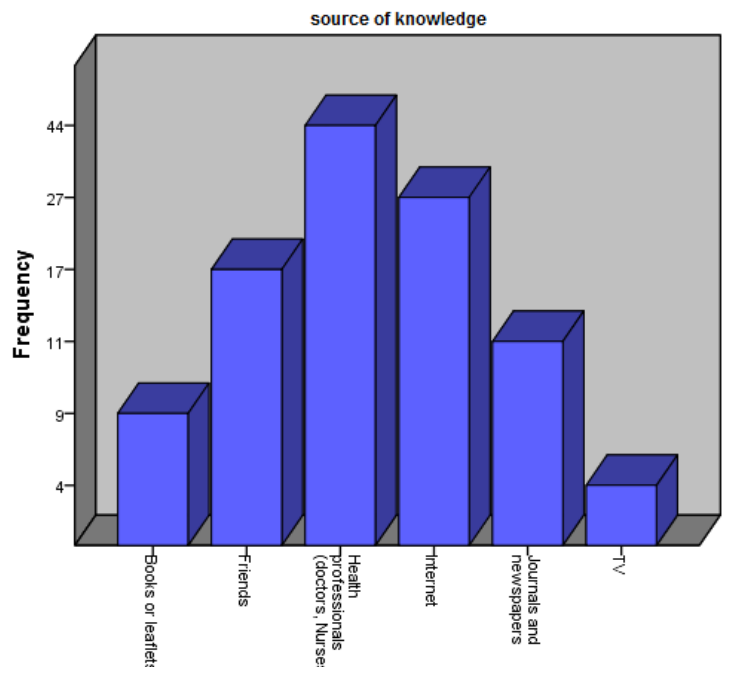

Figure1. Source of knowledge among participants.

Table 2 shows the distribution of answers in each question. In section A (Aetiology of asthma), $100 \%$ of participants said that asthma can be caused by an allergy, air pollution, or any other type of irritant (dust, fumes, etc.); 83.9\% believed that the common cold and exercise can lead to asthma; $79.5 \%$ thought that asthma is a life-threatening condition; and 59.8\% said that asthma is a genetic disease. Only $3.6 \%$ said that they live with an asthmatic person and only $4.5 \%$ believe that asthma could appear without obvious reasons. 
An Investigation of Knowledge, Attitudes, and Practices Concerning Asthma among Patients in Tabuk, Saudi Arabia

Category Yes n (\%) No n (\%) I don't know n (\%)

What are the primary sources of your asthma education and practices?

\begin{tabular}{|l|r}
\hline Journals and newspapers & $\mathbf{1 1}(9.8 \%)$ \\
\hline
\end{tabular}

TV

Books or leaflets

$4(3.6 \%)$

Healthcare professionals (doctors, nurses)

$9(8.0 \%)$

Internet

Friends

$44(39.9 \%)$

$27(24.1 \%)$

$17(15.8 \%)$

Section A: Aetiology of asthma

Asthma symptoms can be caused by:

1. Allergy, air pollution, or any other type of irritant (dust, $112(100)$ fumes, etc.)

2. Living with a person who has asthma.

3. A common cold or exercise.

4. Without obvious reasons.

\begin{tabular}{|l|l|l|}
\hline $\mathbf{4}(83.9)$ & $\mathbf{1 3}(11.6)$ & $\mathbf{5}(4.5)$ \\
\hline $\mathbf{5}(4.5)$ & $\mathbf{1 1}(9.8)$ & $\mathbf{6}(5.4)$
\end{tabular}

5. Asthma is a genetic disease (from a previous generation that already has asthma).

6. Asthma damages the heart.

7. Can asthma be life-threatening?

$5(4.5)$

$11(9.8) \quad 6(5.4)$

$67(59.8)$

39 (34.8)

$6(5.4)$

Section B: Pathophysiology of asthma

\begin{tabular}{l|l|l}
$\mathbf{5 3}(47.3)$ & $\mathbf{5 2}(46.4)$ & $\mathbf{7}(6.3)$
\end{tabular}

\begin{tabular}{l|l|l}
$\mathbf{8 9}(79.5)$ & $\mathbf{1 5}(13.4)$ & $\mathbf{8}(7.1)$
\end{tabular}

1. In asthma, the breathing tubes in the lungs become narrow due to swelling of their walls.

2. In asthma, the breathing tubes also become narrow due to muscle tightening and mucous collection.

3. Symptoms of asthma are breathing difficulty with wheezing or whistling sound.

4. I can judge how severe asthma is.

5. An asthma attack cannot be dangerous.

Section C:Asthma Medications

1. Asthma medicines can be given as tablets/syrup/ inhalers.

2. The best way to take asthma medicines is by inhalation.

\begin{tabular}{|c|c|c|}
\hline $\mathbf{1 0 7}(95.5)$ & $\mathbf{1}(0.9)$ & $\mathbf{4}(3.6)$ \\
$\mathbf{1 1 1}(99.1)$ & $\mathbf{1}(0.9)$ & $\mathbf{0}$ \\
\hline $\mathbf{1 0 9}(97.3)$ & $\mathbf{2}(1.8)$ & $\mathbf{1}(0.9)$ \\
\hline $\mathbf{9 5}(84.8)$ & $\mathbf{1 2}(10.7)$ & $\mathbf{5}(4.5)$ \\
\hline $\mathbf{2 0}(17.9)$ & $\mathbf{8 1}(72.3)$ & $\mathbf{1}(0.9)$ \\
\hline
\end{tabular}

3. Asthma medicines are usually of two types - one to give immediate relief from symptoms (relievers) and another to prevent symptoms (preventers).

4. Medicine for asthma has to be taken while the symptoms persist and then can be stopped.

5. Medicines for asthma have to be taken even after the symptoms are no longer there.

6. With appropriate treatment, most patients with asthma can lead a normal life with no restrictions on activity.

Section E: Beliefs and Attitudes

1. Asthma cannot be cured.

2. Asthma is not a chronic disease; it is an allergy in the chest.

3. Asthma inhalers can cause addiction and cannot be stopped.

4. If the trigger factors can be identified, asthma can be controlled better.

5. Patients with asthma should avoid exposure to $102(91.1)$ environmental tobacco smoke.

6. The health education meets the needs of asthmatic patients and caregivers.

7. Do you think doctors prescribe too much medication?

What do you think patients should do if they have symptoms of asthma?

\begin{tabular}{|l|c|c|}
\hline $\mathbf{8 5}(75.9)$ & $\mathbf{1 5}(13.4)$ & $\mathbf{1 2}(10.7)$ \\
\hline $\mathbf{9 2}(82.1)$ & $\mathbf{1 8}(16.1)$ & $\mathbf{2}(1.8)$ \\
\hline $\mathbf{7 1}(63.4)$ & $\mathbf{1 9}(16.9)$ & $\mathbf{2 2}(19.6)$ \\
& & \\
\hline $\mathbf{8 9}(79.5)$ & $\mathbf{1 7}(15.2)$ & $\mathbf{6}(5.4)$ \\
$\mathbf{1 2}(10.7)$ & $\mathbf{9 1}(81.3)$ & $\mathbf{9}(8.0)$ \\
\hline $\mathbf{9 4}(83.9)$ & $\mathbf{1 8}(16.1)$ & $\mathbf{0}$ \\
\end{tabular}

\begin{tabular}{|l|c}
\hline Go to a hospital facility & $\mathbf{1 0 5}(93.7)$
\end{tabular}

Go to a pharmacy

Get guidance from the internet or others

Self-treatment options (herbs, etc).

\begin{tabular}{|c|c|c|}
\hline $\mathbf{5 6}(50)$ & $\mathbf{3 0}(26.8)$ & $\mathbf{2 6}(23.2)$ \\
\hline $\mathbf{1 1}(9.8)$ & $\mathbf{9 0}(80.4)$ & $\mathbf{1 1}(9.8)$ \\
\hline $\mathbf{6 3}(56.3)$ & $\mathbf{2 6}(23.2)$ & $\mathbf{2 3}(20.5)$ \\
\hline $\mathbf{9 9}(88.4)$ & $\mathbf{1 3}(11.6)$ & $\mathbf{0}$ \\
\hline $\mathbf{0 2}(91.1)$ & $\mathbf{1 0}(8.9)$ & $\mathbf{0}$ \\
\hline $\mathbf{9 7}(86.6)$ & $\mathbf{1 5}(13.3)$ & $\mathbf{0}$ \\
\hline $\mathbf{3 1}(27.6)$ & $\mathbf{6 0}(53.5)$ & $\mathbf{2 1}(18.7)$ \\
\hline
\end{tabular}

$$
105(93.7)
$$

0 (0)

$7(6.2)$

$\mathbf{0}$ 
An Investigation of Knowledge, Attitudes, and Practices Concerning Asthma among Patients in Tabuk, Saudi Arabia

\begin{tabular}{|l|c|}
\hline I do not use an inhaler for a longer period because I think: \\
\hline It has side effects & $\mathbf{5 5}(49.1)$ \\
\hline It causes obesity & $\mathbf{5}(4.4)$ \\
\hline It can cause other diseases & $\mathbf{1 0}(8.9)$ \\
\hline It has no effect on the symptoms & $\mathbf{1 1}(9.8)$ \\
\hline I should avoid practicing exercise & $\mathbf{1 8}(16.0)$ \\
\hline It is difficult to use medications & $\mathbf{1 3}(11.6)$ \\
\hline
\end{tabular}

\section{Symptoms and severity}

Participants demonstrated high levels of knowledge about the symptoms and severity of asthma. Almost all participants knew that asthma is characterised by narrowing in the breathing tubes due to swelling in their walls (99\%) or tightening of muscles and mucus collection $(97 \%)$ and that asthma causes wheezing or whistling sound (96\%). Unsurprisingly, $85 \%$ stated that they can judge the severity of asthma and only $18 \%$ believed that asthma is not a dangerous disease.

\section{Asthma Medications}

When participants' knowledge of asthma medication was assessed, $82 \%$ reported that inhalers are the best medication to alleviate asthma symptoms. When participants were asked when to stop using medicines, $80 \%$ stated that it is safe to stop medication use immediately after the symptoms disappear; only $11 \%$ said that medication use should be continued even if symptoms had stopped.

\section{Beliefs and Attitudes}

Approximately $91 \%$ of the total population believed that patients with asthma should avoid smoking areas, and about $88 \%$ said that asthma can be controlled better if the triggering factors are identified. Educating families and caregivers of asthma patients was important to $87 \%$ of participants and only $10 \%$ said that asthma is not a chronic disease but rather an allergy in the chest. However, participants were uncertain if asthma could be cured: $50 \%$ said it can be cured; $27 \%$ answered that it cannot be cured; and $23 \%$ said they have no idea.

When participants were asked about what patients with asthma should do if they experience symptoms, 94\% stated that patients should go directly to hospital and only $6 \%$ said that patients can simply get advice from the internet. No respondents reported that patients should receive assistance from a pharmacy or from self-treatment options such as herbs. In addition, when participants were asked why patients should stop using their inhaler at some point, $49 \%$ believed that it is to avoid side effects from the inhaler; $16 \%$ thought that inhalers prohibited patients from exercising; and only $4 \%$ said that patients should not overuse inhalers because it leads to obesity.

No significant relationship was found between demographic characteristics and the knowledge and attitudes of the participants.

\section{DISCUSSION}

In this study, we investigated knowledge and attitudes toward asthma among 112 patients previously diagnosed with asthma. Patient characteristics were similar to those in other studies, with an almost equal proportion of men and women (23). However, the educational levels of respondents and the distribution of answers to the knowledge and attitude questions varied.

In general, slightly more than half of respondents had sufficient knowledge of asthma. In our study, $39.9 \%$ of participants stated that healthcare professionals (doctors and nurses) were the primary source of their knowledge; $24.1 \%$ said that they had obtained information from the internet; and only $9.8 \%$ gained their knowledge from newspapers or journals and only $3.6 \%$ from television. This is consistent with several previous studies, which found that healthcare professionals were the main source of knowledge for asthmatic patients (24-25). This consistency may be because healthcare professionals in these countries consider patient education a priority in the treatment process. However, in other studies, it has been reported that healthy adult received most of their information from television, newspaper, family members, and their friends $(21,25,26)$. In one study, participants obtained this knowledge from family (21), while participants in another study stated that television (57.5\%) and newspapers (37.5\%) were their primary information sources (25).

Overall, $100 \%$ of respondents knew that asthma can be irritated by allergy, air pollution, or any other irritant such as dust or fumes. Only $3.6 \%$ thought that asthma is a contagious disease. This 
An Investigation of Knowledge, Attitudes, and Practices Concerning Asthma among Patients in Tabuk, Saudi Arabia

high level of knowledge may result from updated knowledge and previous experience. About $49 \%$ of patients in our study said they do not use an inhaler for long periods because they believe it has side effects. This is also consistent with a study on asthma patients in the Saudi Arabia, which found that 24\% (26) of patients cited the same reason to explain why they do not use inhalers for long period and do not comply with their doctors' instructions. In our study, $76 \%$ of participants believed that inhalers can alleviate symptoms of asthma, which mirrors population knowledge data in Abu Dhabi (70\%) (27).

The guidelines from the Global Initiative for Asthma state that an asthma education program can improve patients' awareness. Knowledge about the prevailing perceptions among the patient population would be the first step in achieving this. Designing educational programs for patients, families, and caregivers may help slow the increase in asthma morbidity and mortality rates (28). For example, if asthmatic patients practice breathing exercises regularly, this could strengthen respiratory muscles and alleviate asthma attacks (29).There is global problem with asthma management among adult patients, either under treatment due to ignorance or distorted information/knowledge of patients about their diseases (30).

This study may be an important step in future guidance for the patients with asthma, as the gaps of knowledge were identified, the patients' beliefs to provide effective asthma care. Increasing the awareness of patients towards asthma will result in a well-controlled asthma, which will enhance the overall health of asthmatic patients, decrease contact with healthcare services, and decrease the number of hospitalizations caused by asthma. Furthermore, bridging the gaps of knowledge related to asthma will result in improving the quality of life for asthmatic patients (31).

With regards to the limitation of this study, our study was limited by a small sample size, specific age, which makes the generalizability of the results difficult. Therefore, further studies on larger populations from several regions are required. In addition, we recommend an interventional study to compare knowledge and attitudes between groups to assess the effectiveness of education programs.

\section{CONCLUSION}

In conclusion, this study and discussion of pertinent literature found epidemiological trend of asthma concerns worldwide. Effective periodic questionnaires must be developed to accurately determine the gap between the knowledge and practices of patients with asthma. The findings of this study have important implications for physicians dealing with patient's knowledge, attitudes, and practices concerning asthma management and for health planners to adopt strategies to address and implement education, treatment plans and develop methods to raise awareness among patients and their families and caregivers. Healthcare providers must be fully aware of health literacy barriers as a major cause of poor cognitive control of asthma. Finally, healthcare professionals, patients, and communities should be considered in any treatment plan. Further studies are needed to regularly explore traditional therapies stand alone and also their combined use with modern medicines in larger samples in Saudi Arabia and other Arabian Gulf countries.

\section{REFERENCES}

[1] Global Initiative for Asthma (GINA) (2019). Global Strategy for Asthma Management and Prevention. Available online: https:// ginasthma.org/

[2] National Heart, Lung, and Blood Institute (2016). National Asthma Education and Prevention Program. Available online: https://www.nhlbi.nih.gov/about/org/naepp/.

[3] Douglas, J. (2010). Occupational asthma. Practice Nurse, 40(4), 19-20.

[4] Al-Moamary, M. S., Alhaider, S. A., Idrees, M. M., Al Ghobain, M. O., Zeitouni, M. O., AlHarbi, A. S., et al. (2019). The Saudi Initiative for Asthma - 2019 update: Guidelines for the diagnosis and management of asthma in adults and children. Annals of Thoracic Medicine, 11(1), 3-42.

[5] Al-Moamary, M. S. (2012). The Saudi Initiative for Asthma. Annals of Thoracic Medicine, 4, 216-233.

[6] Al Frayh, A., Shakoor, Z., Elrab, M., Hasnain, S. (2001). Increased prevalence of asthma in Saudi Arabia. Annals of Allergy, Asthma and Immunology, 86(3), 292-296.

[7] Al Frayh, A., Bener, A., Al Juwadi, T.Q. (1992). "Prevalence of asthma among Saudi 
An Investigation of Knowledge, Attitudes, and Practices Concerning Asthma among Patients in Tabuk, Saudi Arabia

school children," Saudi Medical Journal, 13, 521-524,

[8] Nahhas, M., Bhopal, R., Anandan, C., Elton, R., Sheikh, A. (2012). Prevalence of allergic disorders among primary school-aged children in Madinah, Saudi Arabia: Two-stage crosssectional survey. Plos One, 7(5): E36848.

[9] Alqahtani, J.M., Asaad, A.M., Awadalla, N.J., Mahfouz, A.A. (2017). Environmental Determinants of Bronchial Asthma among Saudi School Children in Southwestern Saudi Arabia. International Journal of Environmental Research and Public Health, 14(1), 22. http://doi.org/10.3390/ijerph14010022

[10] BinSaeed, A. (2015). Asthma control among adults in Saudi Arabia. Saudi Medical Journal, 36(5), 599-604.

[11] BinSaeed, A.A., Torchyan, A.A., Alsadhan, A.A., Almidani, G.M., Alsubaie, A.A., Aldakhail, A.A., AlRashed, A.A., AlFawaz, M.A., Alsaadi, M.M. (2014). Determinants of asthma control among children in Saudi Arabia. Journal of Asthma, 51(4), 435-9.

[12] Hussain, S.M.,Farhana, S.A., Alnasser, S.M. (2018). "Time Trends and Regional Variation in Prevalence of Asthma and Associated Factors in Saudi Arabia: A Systematic Review and Meta-Analysis," BioMed Research International, vol. 2018, Article ID 8102527, 9 pages, https://doi.org/10.1155/2018/8102527.

[13] Moradi-Lakeh, M.,Bcheraoui, C.E.,Daoud, F. (2015). "Prevalence of asthma in Saudi adults: findings from a national household survey," BMC Pulmonary Medicine, 15, 10-1186.

[14] Al-Atawi, A. (2017): The Effectiveness of Asthma Education Approaches for Children: Group versus Individual Education. Biomedical Journal of Scientific \& Technical Research 1(3)- 2017, https://doi.org/10.26717/BJSTR. 2017. 01.000306.

[15] Al-Ghamdi, B., Mahfouz, A., Abdelmoneim, I., Khan, M., Daffallah, A. (2008). Altitude and bronchial asthma in Southwestern Saudi Arabia. East Mediterranean Health Journal, 14(2), 17-23.

[16] Leickly, F. E. (2004). Asthma and adherence: How to get your child to take medications. Asthma Magazine, 9(3), 10-12.

[17] WHO. Asthma Fact-sheet., Geneva, World Health Organization, http://www.who.int/media centre/factsheets/fs307/en/.

[18] Sodhi, R. et al. (2013).A study to know the knowledge, attitude, and practices of patients of bronchial asthma. International Journal of Medicine and Public Health 3, 159
[19] Prasad R, Gupta R, Verma SK. A study on perception of patients about bronchial asthma. Indian J Allergy Asthma and Immunol. 2003; 17:85-7.

[20] Gaude Gajanan, Nicasia Fernandes, Sindhury Avuthu, JyothiHattiholi. (2015) Assessment of Knowledge and Attitude of Bronchial Asthma Patients Towards Their Disease. Journal of Evolution of Medical and Dental Sciences Vol. 4, Issue 90, November 09; Page: 15508-15514, DOI: $10.14260 /$ jemds/2015/221923

[21] Al-Anazi, A, AL Moamary, M, Ismaeli, T, Alanazi, A, Olayan, L, Alanazi, A, Qureshi, S. (2014) The reliability of the Arabic version of the asthma knowledge questionnaire and assessment of the level of asthma awareness among parents of children with asthma in Saudi Arabia. Middle-East J. Sci. Res. 20 (4):

[22] Nguyen, V. N., Huynh, T., Chavannes, N. H. (2018). Knowledge on self-management and levels of asthma control among adult patients in Ho Chi Minh City, Vietnam. International Journal of General Medicine, 11, 81-89. https://doi.org/10.2147/IJGM.S157050.

[23] Al-Ali, L.A., Al-Jasmi, S.A., Al Yammahi, L.M., Syeed, A., Darwish, E.A. (2019). Parental knowledge, attitudes, and practices regarding the use of prescribed inhalers in asthmatic children attending Ambulatory Healthcare Services Clinics. Ibnosina J Med Biomed Sci.11(2)68.

[24] Chai, S.M., Tan, K.L., Wong, J.L., Eng, P. (2004). Asthma knowledge among adult asthmatic outpatients in a tertiary care hospital. Asian Pac J Allergy Immunol.22 (2-3)81.

[25] Singh H. 1, Pal S. S. 2, Abraham J. 3, kaur A. (2019). A Study on Knowledge, Attitude and Practice of Asthmatic Patients towards Inhaler Use. Journal of Dental and Medical Sciences (IOSR-JDMS). Volume 18, Issue 4 Ser. 10 (April. 2019), PP 06-10 www.iosrjournals.org

[26] Donques AA, Alaki E, Almazyad W, Almutairi A (2017) Knowledge and Perception of Asthmatic Patients and their Family towards Asthma Disease and Management in King Saud Medical City, Riyadh, KSA. J ClinRespir Dis Care 3: 128. doi: 10.4172/2472-1247.1000128

[27] Mohamed, O. M. I., Karameh, W. K.(2015) Knowledge, attitude and behaviour of asthmatic patients regarding asthma in primary care setting in Abu Dhabi, United Arab Emirates.world family medicine journal. volume 13 Issue 5.

[28] Hassed, C. (2005) An integrative approach to asthma. AustFam Physician.34 (7)573.

[29] Mohamed, O.M.I., Karameh, W.K. (2015). Knowledge, attitudes, and behaviour of asthmatic patients regarding asthma in primary care setting in Abu Dhabi, United Arab 
An Investigation of Knowledge, Attitudes, and Practices Concerning Asthma among Patients in Tabuk, Saudi Arabia

Emirates. World Fam Med J Inc Middle East J Fam Med.99(2129)1-8.

[30] Gibson PG, Wilson AJ. (1996) The use of Continuous Quality improvement methods to implement practise guidelines in asthma. J Qua! Clin Pract $16: 87-102$.
[31] Majellano EC, Clark VL, Winter NA, Gibson PG, McDonald VM. (2019) Approaches to the assessment of severe asthma: barriers and strategies. J Asthma Allergy; 12:235-251 https://doi.org/10.2147/JAA.S178927.

Citation: Abeer Alatawi \& Ali Alghamdi, "An Investigation of Knowledge, Attitudes, and Practices Concerning Asthma among Patients in Tabuk, Saudi Arabia”, International Journal of Research Studies in Medical and Health Sciences. 2020; 5(5): 20-27.

Copyright: (C) 2020 Abeer Alatawi \& Ali Alghamdi, This is an open-access article distributed under the terms of the Creative Commons Attribution License, which permits unrestricted use, distribution, and reproduction in any medium, provided the original author and source are credited. 